Cynthia A. Ramírez Félix 


\section{La voluntad de conocimiento desencajada de su finalidad original, pero como supuesto de la voluntad de poder}

\section{Resumen}

En el presente ensayo se analiza el origen del concepto denominado por Nietzsche: voluntad o instinto de conocimiento. Siguiendo al autor, se pretende mostrar cómo el impulso hacia el conocimiento no es meramente racional, sino fisiológico; y cómo, no obstante, a través del tiempo se ha perdido el origen vital de este impulso, el cual se ha utilizado para fines contrarios a la preservación de la vida. A manera de consideración final, se expone lo que parece ser una solución nietzscheana para entender la finalidad del conocimiento, es decir, la argumentación a favor del conocimiento como un instinto o voluntad que impele a la superación en la existencia.

\section{La voluntad de poder}

La voluntad de transformar, de crear, de comprender, de aprehender, es lo que Nietzsche denomina voluntad de poder, la cual se manifiesta en todo lo vivo, en todo lo que quiere expandirse más allá de su ser. Toda la vida es voluntad de poderío, incluso en los seres más débiles o de inteligencia precaria. Todo lo que vive desea más que su propia existencia.

Así pues, donde hay vida $-y$ sólo ahí-, necesariamente hay voluntad de poder, «la voluntad de poder sólo se da en un ser vivo, sólo donde hay vida también hay voluntad; ipero no voluntad de vida, sino voluntad de poder!». ${ }^{1}$ Se separa, así, Nietzsche de los filósofos que definen la voluntad como instinto de conservación del ser o como voluntad de existir. ${ }^{2}$ Pues no es posible que el ser que ya existe aspire a la existencia o que algo que aún no existe desee existir.

1 F. Nietzsche, Así hablaba Zaratustra. De la superación de sí mismo, st, México, Leyenda, 2001, p. 71.

2 Cfr. B. Spinoza, Ética demostrada según el orden geométrico; A. Schopenhauer, El mundo como voluntad y representación. 
La voluntad de poder no es perseverar en la existencia, sino alcanzar la superación; su carácter es fisiológico, es decir, su raíz es biológica, pues todo lo que vive, inconscientemente tiende a expandir sus expectativas más allá de su existencia. En este aspecto, la naturaleza representa el mayor paradigma de la voluntad de poder, puesto que en ella siempre hay abundancia, siempre da más de lo que es necesario, no sigue una lógica de lo necesario y útil; la naturaleza, al mismo tiempo que es la auténtica voluntad de poder, es también el caos personificado.

Otra forma, en la cual se manifiesta la voluntad de poder, es a través de la indiferencia hacia la vida misma; el hecho mismo en que un guerrero se entrega a la batalla y sacrifica su vida con la finalidad de salvar a su Estado o a su patria. Lo vivo siempre expresa su voluntad de poder a través de la búsqueda de oposiciones, de dificultades que le permitan expresar su poderío, es decir, lo vivo sacrifica su vida y felicidad en aras del poder. La voluntad de poder es el impulso vital que cada ser tiene y en el que siempre $-y$ en esto radica su carácter trágico- se termina por suprimir al ser.

La voluntad de poder se da en todo ser vivo, a pesar de que en algunos no se manifieste con gran claridad, tal es el caso del hombre débil, donde la voluntad parece guiarse, solamente, por el «instinto de conservación de la especie». Sin embargo, aun donde no sea tan evidente, la voluntad existe de cierta manera, ya sea en el esclavo, en el siervo o en el débil. Todo ser tiene en su constitución fisiológica el instinto de poder, de mandar. En este caso, el esclavo o siervo obedece al amo porque su instinto lo invoca a mandar. Se somete al fuerte para después poder dominarlo, le quita el poder no de frente, sino subrepticiamente; se vale de artimañas, no es sincero con los demás $y$, de esta manera, cuando el tiempo es propicio y la oportunidad lo amerita, ocupa su lugar: "y también allí donde hay sacrificio y servicio abnegado y mirada amorosa hay la voluntad de ser amo. Por caminos clandestinos entra secretamente el débil en la fortaleza y hasta el corazón del poderoso, y allí roba poder». ${ }^{3}$

Se muestra, entonces, cómo la voluntad de poder se encuentra en todo ser vivo; en unos se expresa de manera más genuina, fuerte y vivaz, pero en otros se activa por el resentimiento, en estos casos encontramos seres reactivos.

3 Idem. 
En el hombre fuerte la voluntad de poder se manifiesta en el hecho de querer ser señor, de querer dominar, y sólo en la medida en que se es activo se puede obtener el poder. Sin embargo, como todo lo viviente obedece siempre a algo más (el poder), el hombre activo siempre pondrá en segundo lugar su vida y felicidad y, más aún, su propio poder. Por ejemplo, en la creación de los Estados, el hombre funda leyes y debe someterse a éstas aunque le cueste el destierro o la vida, hecho que ilustra Edipo Rey. Al haber decretado el destierro y malaventuranza al asesino de Layo, tuvo que someterse él mismo a la ley:

Yo, mísero, el más noble hijo de Tebas, me privé a mí mismo de esto, yo que decreté que todos repelieran al sacrilegio, a aquél cuya impureza mostraban los dioses $[\ldots]$ iy del linaje de Layo! ${ }^{4}$

La voluntad de poder es siempre la que quiere superarse, es el impulso a un fin más elevado, a algo supremo. Pero también es voluntad de contradicción, puesto que el mismo hombre tiene que suprimirse a sí mismo, tiene que someterse y obedecerse a sí mismo para, de esta manera, conseguir el poderío:

Que yo deba ser lucha y devenir y fin y la contradicción de los fines, ¡ah, quien adivine mi voluntad adivina también los caminos tortuosos que ella tiene que recorrer! Cualquiera que sea mi obra y mi amor a ésta, pronto tengo que ser el contrincante de mi obra y mi amor; así lo quiere mi voluntad". ${ }^{5}$

La voluntad de poder en Nietzsche es siempre una totalidad, se «interpreta como esfera del poder no sólo al hombre y el mundo del hombre, sino también la naturaleza». ${ }^{6}$

Con el concepto de voluntad de poder parecerá que Nietzsche trata de humanizar y racionalizar la naturaleza, pero el hecho de que la voluntad de poder o de conocimiento atrape o avasalle la naturaleza no significa que la naturaleza tenga deseos o ideales, sino todo lo contrario: «hace que lo cruel y también inhumano, a saber, las luchas de

4 Sófocles, Tragedias, Ayax, Antígona, Edipo Rey, Salvat, 1969, p. 173.

5 F. Nietzsche, op. cit.

6 R. Safranski, Nietzsche. Biografía de su pensamiento (trad. Raúl Gabás), España, Tusquets, 2002, p. 308 . 
poder; se le reflejan en la naturaleza como su misterio interior». ${ }^{7}$ En este sentido, no debe entenderse la voluntad de poder como un concepto o criterio metafísico para expresar la secreta y oscura verdad de la vida. La voluntad de poder que nos presenta Nietzsche es sólo un criterio hermenéutico para interpretar la naturaleza, su engranaje es la descripción, tras bambalinas, detrás de toda consideración científica o religiosa. Es la manera de interpretar todo lo vivo; en su esencia existe el buscar la superación de su propio ser, no sólo el conservar el ser. Es una interpretación de la vida, libre de prejuicios morales, neutral. La voluntad de poder abraza lo monstruoso y lo trágico de la vida, rechazando la unidad y la quietud con que se ha concebido durante miles de años.

\section{La voluntad de conocimiento es una forma más de la voluntad de poder}

Se ha tratado de esclarecer de manera breve lo que es la voluntad de poder, sin embargo, no hemos hecho mención de sus distintas manifestaciones que, en última instancia, son los instintos o afectos. El hombre, puesto que tiene distintas necesidades, tendrá instintos diversos, es decir, los instintos corresponden a, o tienen una fundamentación biológica. Los instintos o la voluntad de poder pretenden abarcar o tener el dominio sobre todo lo que les está permitido; los instintos son potencialidades que pretenden su constante actualización, tales como el instinto sexual, de felicidad, de placer, etcétera. Entonces, al conglomerado de instintos es a lo que se denomina voluntad de poder. Los instintos son diversas formas manifiestas de la voluntad de poder.

Para que un instinto sobresalga entre los demás, tendrá por fuerza que dominar a los otros. Tal es el caso de la voluntad o instinto de conocimiento, para sobresalir tendrá que doblegar y subyugar a los demás. Estamos hablando entonces, si todo va claro, de que la voluntad de conocimiento es un instinto $y$, además, es fundamental. El conocimiento, el interpretar la naturaleza, no tiene como origen un carácter lógico, una racionalidad o capacidad del ser humano independiente del carácter biológico del hombre:

7 Idem. 
Pero quien examine los instintos fundamentales del hombre con el propósito de saber hasta qué punto precisamente ellos pueden haber actuado aquí como genios inspiradores encontrará, que a todos ellos, le gustaría mucho presentarse justo a sí mismos como finalidad última de la existencia y como legítimo señor de todos los demás instintos. ${ }^{8}$

Lo que pretende la voluntad de poder es imponerse al desorden desmedido que representa la naturaleza, y crear su propio orden bajo leyes y conceptos, puesto que es imposible por otros recursos, dada su indiferencia y libre de intención, o como la describe Nietzsche «libre de piedad y de justicia, que es feroz y estéril e incierta al mismo tiempo, imaginaos la indiferencia misma con poder». ${ }^{9}$ Será entonces por el pensamiento, la aprehenderá y penetrará a través de la interpretación.

Frente a la naturaleza, monstruosa en crueldad, el hombre, por otro instinto, el instinto de evadir el miedo y la inseguridad, buscará hacer conocido lo no conocido, ya que en primera instancia, la fuerza del conocimiento no reside en su veracidad, sino en su condición vital:

El reducir algo desconocido a algo conocido alivia, tranquiliza, satisface, proporciona además un sentimiento de poder. Con lo desconocido vienen dados el peligro, la inquietud, la preocupación, el primer instinto acude a eliminar esos estados penosos. ${ }^{10}$

Encontramos que, el conocimiento no sólo es una aspiración o deseo, sino que es un principio en la vida, es una necesidad para enfrentar lo desconocido. De esta manera, lo que se tiene por verdadero es lo que en un primer momento ha aclarado lo desconocido y, al mismo tiempo, lo que nos representa un placer. Entonces, podemos decir que el concepto de causalidad nació como un efecto reactivo al sentimiento del miedo; responder al por qué no es demostrar la causa por ella misma, metodológicamente creada, sino como una causa tranquilizadora que libera y alivia. El instinto causal tiene que

8 F. Nietzsche, Más allá del bien y el mal, $8^{\text {a. }}$ reimp., Madrid, Alianza, 1997, p. 26.

$9 \quad$ Ibidem, p. 28.

10 F. Nietzsche, Crepúsculo de los ídolos (trad. Andrés Sánchez Pascual), 15a. reimp., Madrid, Alianza, 1997, p. 66. 
responder frente a lo nuevo, a lo extraño, es pues, en palabras de Nietzsche:

Una especie escogida y privilegiada de aclaraciones, aquellas con las que de manera más rápida más frecuente queda eliminado el sentimiento de lo extraño, [...] las aclaraciones más habituales. ${ }^{11}$

Es contrario pensar que el desarrollo intelectual en el hombre nace como un plus, indiferente a las condiciones biológicas, esto significa negar las fuerzas de los instintos. Es pretender que la razón se desarrolló para indagar mundos abstractos y consideraciones frías y lógicas negando así la propia vida. Por el contrario, el pensar consciente es un instinto. Conocer es hacer aprehensible el mundo, dominarlo, interpretarlo; lo que se tiene por verdadero, la verdad, es lo que beneficia y es útil a la vida, por ello, el concepto de la verdad es tan anhelado, puesto que es el que proporciona tranquilidad, placer, seguridad y poder.

De esta manera, el conocimiento se convierte en una de las primeras necesidades, además de ser un poder que siempre va en crecimiento:

No sólo la utilidad y el placer, sino toda clase de impulsos tomaron parte en la lucha por las verdades, la lucha intelectual llegó a ser ocupación, incitación, oficio, deber, dignidad: el conocimiento y el impulso a la verdad así se integraban, al fin, como necesidad entre las necesidades. ${ }^{12}$

A esta altura queda demostrado cómo el instinto de conocimiento tiene una raíz fisiológica o biológica. Y terminamos por pensar que la mayor parte del pensamiento consciente debe ser puesto entre el número de las actividades instintivas, sin exceptuar la reflexión filosófica. El impulso que hace penetrar en la naturaleza es el impulso al mismo tiempo de crearla.

Para aclarar lo anterior, diremos que el hombre como ser indefenso, sin las cualidades para desenvolverse en la naturaleza, se siente desprovisto de poder, pero su debilidad radica principalmente en el desconocimiento; a diferencia de los demás seres,

11 Idem.

12 F. Nietzsche, Gaya ciencia, Madrid, Akal, 2001, p. 151. 
éstos sí, provistos de grandes atributos para enfrentarse a la naturaleza. Frente a lo desconocido, los hombres buscan siempre esquivar y no encontrarse nunca con el sentimiento de miedo que provoca lo extraño. Y puesto que el mundo y la naturaleza son un caos, sin leyes, razón ni finalidad, el hombre buscará por todos los medios conocerlo, interpretarlo, asimilarlo a su intelecto (causalidad). Por ello mismo, el hombre crea otro mundo, un mundo que no le sea hostil. Así pues, el mundo ordenado con sentido es una creación que el hombre, bajo el instinto causal o de conocimiento, ha interpuesto entre él y el mundo real.

La concepción que se ha tenido del mundo, nos dice Nietzsche, es falsa, pero no por ello mismo el intelecto resulta menospreciado, más aún, las ideas y concepciones sobre el mundo en distintos momentos de la historia han servido para conservar y perseverar en la existencia. Ni todas las ciencias, ni todas las disciplinas pueden aprehender de forma total y real el mundo. Nietzsche intenta salir de estas pretensiones al declarar que el mundo no tiene rasgos aprensibles por el intelecto, y por ello mismo, es imposible representarlo correctamente. $^{13}$

\section{Los griegos como ejemplo paradigmático de la voluntad de poder}

En un primer momento nos referimos a los albores del conocimiento, lugar del hombre genuino, en este estadio el instinto de conocimiento obedeció a impulsos positivos. Entiéndase positivo en el sentido de mejorar la existencia, de superar las condiciones primarias, es decir, se poseía el instinto de conocimiento para tener poder sobre la naturaleza y sobre los demás hombres, sobre lo que es útil, lo que ensancha y dilata la existencia. En fin, el conocimiento tenía propósitos vitales.

Una ejemplificación fidedigna de la expresión de la voluntad de poder, en este primer estadio, la encontramos en los griegos. Nunca la voluntad de poder se manifestó tan claramente como en la antigua Grecia. Nos referimos principalmente a lo expresado en la Ilíada, fiel retrato de su cultura.

13 Cfr. A. Nehamas, Nietzsche la vida como literatura, México, Fondo de Cultura Económica, 2002. 
En los griegos de la época heroica, la dominación que ejerce el instinto de conocimiento (necesario para la vida) sobre los demás instintos es sólo de dominación, pero no de aniquilación. Se mantiene un cierto equilibrio entre lo racional y lo fisiológico, encontramos que el hombre es un ser psicofisiológico; su estado natural tiene un lugar privilegiado y se hace ver cuando es necesario, por ello mismo, sus instintos son su principal guía, en cambio la razón es sólo secundaria.

Los griegos, aun conscientes de la verdadera finalidad del instinto de conocimiento, y del placer que suscita el tener el dominio y el poder, saben que lo que ellos denominan conocimiento es sólo interpretación del mundo y de los hechos. Utilizan el conocimiento para poder tener dominio sobre la naturaleza, sus juicios de valor tienen presupuestos fisiológicos, juzgan como bueno todo lo saludable, poderoso y feliz; contrario a lo débil, que se juzga: malo, infeliz, bajo $y$ detestable.

De acuerdo con la interpretación de Weil Simone, el tema principal de la Ilíada es la fuerza, ahí el hombre aparece aplastado por su propia fuerza:

La fuerza es lo que hace una cosa de cualquiera que le esté sometido. Cuando se ejerce hasta el extremo, hace del hombre una cosa en el sentido más literal, pues hace de él un cadáver. ${ }^{14}$

La fuerza o voluntad de poder lleva germinalmente la autosupresión del ser que la posee. El hombre, embriagado de poder, se somete a sí mismo; en la guerra no responde su "instinto de conservación", quiere explayar esa fuerza incluso a costa de su vida.

Para toda creación es necesario el dolor, así lo entendieron los griegos; es necesaria la crueldad. Tanto la naturaleza como el hombre, junto con su voluntad de poder, están sometidos a la crueldad. Es la guerra, entonces, un festival de la crueldad necesario para el desarrollo y transcurso de la vida, y un efecto de la voluntad de poder.

$\mathrm{Y}$ es, precisamente en ellos, los griegos, en quienes existe una genuina e inocente necesidad de crueldad. Es decir, helenos y troyanos no se avergonzaban de su crueldad, no se avergonzaban de sus instintos, no existía pues, una vergüenza del hombre por el hombre:

14 S. Weil, La fuente Griega, (trad. José Luis Escartin), Madrid, Trotta, 2005, p. 15. 
En aquella época en que la humanidad no se avergonzaba aún de su crueldad, la vida en la tierra era más jovial [... El El oscurecimiento del cielo situado sobre el hombre ha aumentado siempre en relación con el acrecentamiento de la vergüenza del hombre ante el hombre. ${ }^{15}$

Los griegos, orgullosos de sus instintos, tenían una vida más rica y abundante, pero por ello mismo trágica y cruel, ya que la naturaleza es precisamente esto último.

No obstante, la crueldad no debe entenderse en sentido negativo, sino bajo la forma de un necesario, como algo inevitable en la vida. Es aquí donde precisamente radica el heroísmo y virtud de los griegos: no se limitaban, no delimitaban sus instintos para evitar la crueldad o la muerte.

Es, entonces, en la guerra donde explota el verdadero carácter del hombre pletórico de vida:

Si todos están destinados al nacer a sufrir la violencia, es ésa una verdad que la fuerza de las circunstancias oculta al espíritu de los hombres [... ] Donde el pensamiento no tiene lugar, no hay justicia ni prudencia. Por eso mismo esos hombres armados actúan con dureza y alocadamente. ${ }^{16}$

El hombre quiere simplemente todo, si bien hay un dominio de un instinto sobre otro (como el instinto de apoderamiento o el de conocimiento). No obstante, en los griegos, la supremacía de un instinto no niega a los demás; más aún los griegos explotan cada instinto en su tiempo oportuno, por esto mismo saben cómo guiarse a través de sus instintos. Necesitan la actividad de sus funciones fisiológicas, buscan por instinto lo que es sano, buscan y encuentran todo lo que les fortalece. Por ello las constantes batallas, puesto que la paz es sólo hibernación de las capacidades:

Ni siquiera una vez probada, deja la guerra de parecer un juego. La necesidad propia de la guerra es terrible, muy distinta a la de los trabajos de la paz; el alma no se le somete más que cuando

15 F. Nietzsche, Genealogía de la moral, (trad. Andrés Sánchez Pascual), 2a. reimp., Madrid, Alianza, 2000, p. 87.

16 S. Weil, op. cit., p. 24. 
ya no puede escapar, y en tanto escapa a ella, pasa días vacíos de necesidad, días de juego, de sueño, arbitrarios e irreales. ${ }^{17}$

El sujeto de la voluntad de poder contiene en sí la voluntad de autosuprimirse, su propia voluntad le conmina a enfrentarse a su destino, en pro de algo mejor. Los griegos saben que la condición del hombre es finita y por ello mismo adoran la vida, explotan todos sus instintos, puesto que saben que sólo existe esta vida y que no hay una finalidad; no hay un más allá:

El pensamiento de la muerte no puede ser sostenido, sino por destellos, desde el momento en que se siente que la muerte es, en efecto, posible [...] para aquellos cuya alma está sometida al juego de la guerra, la relación entre la muerte y el futuro no es la misma que para los demás hombres. Para los otros, la muerte es un límite impuesto de antemano al porvenir; para ellos, es el porvenir mismo, el porvenir que le asigna su profesión [...] el pensamiento se hace incapaz de pasar de un día al siguiente sin afrontar la imagen de la muerte. ${ }^{18}$

\section{La voluntad de conocimiento desencajada de su finalidad original, pero necesaria bajo el presupuesto de la voluntad de poder}

Como hemos visto, el ser poseedor de la voluntad de poder, por su misma fuerza y por alcanzar algo supremo, termina autosuprimiéndose; todo lo bueno y poderoso termina por suprimirse a sí mismo. La voluntad de poder no es voluntad de vivir, sino es poder de crear un todo coherente, vivo, y es destructivo sólo en la medida que crea, destruye para crear.

Grecia no fue la excepción, como sujetos de poder, los griegos necesitaban suprimir ciertos instintos, para que la sociedad y el hombre como individuo florecieran y se desarrollaran.

Acostumbrados a seguir la fuerza de sus instintos, a que éstos fueran la principal guía en la vida, y de pronto despojados de su posición de mentor, ahora su única función será causar molestia a la

17 Ibidem, p. 30.

18 Ibidem, p. 31. 
nueva directriz. La razón tomará el papel de guía y domadora de los instintos:

Felizmente adaptados a la selva, a la guerra, al vagabundaje, a la aventura, -de un golpe todos sus instintos quedaron desvaloralizados y en "suspenso" [... no tenían ya, para este nuevo mundo desconocido, sus viejos guías, los instintos reguladores e inconscientemente infalibles-, ¡ estaban reducidos, estos infelices, a pensar, a razonar, a calcular, a combinar causas y efectos, a su conciencia, a su órgano más miserable y más expuesto a equivocarse! $!^{19}$

El hombre queda reducido sólo a pensar, a crear causalidades, ya no tiene los instintos inconscientes que regulaban la vida de manera justa con su naturaleza y acorde también con su hábitat. La domesticación de los instintos entraña y da a luz un malestar, ya que los instintos no son libres de exteriorizarse, más aún, acaban volviéndose hacia ellos mismos, guardándose en algo oscuro y profundo que Nietzsche denomina alma, aquel gran receptáculo que guarda la lucha de instintos desesperados por salir, pero que en su intento sólo han creado un abismo profundísimo; ahora el hombre, nos dice Nietzsche, se ha vuelto profundo.

No obstante, según el mandato de la voluntad de poder, esto es totalmente necesario, ya que la voluntad de poder está sujeta intrínsecamente a la autosupresión del ser que la posee; en sí, la voluntad de poder lleva consigo el impulso a socializarse a salir de la barbarie, el impulso de cierta manera a que los instintos sean sublevados a su separación del estado animal.

A partir de esta separación el hombre tendrá que regirse por el intelecto, éste es ahora su único medio para la conservación y desarrollo de las fuerzas. Pero es también el impulso a fingir, a crear fantasías y metáforas. Desposeído de su primera directriz, ahora tendrá que guiarse por el intelecto, el cual busca explicar e interpretar todo a su alrededor, ahora tendrá que inventar ciertos lineamientos en los hechos, es decir, tendrá que someter la realidad a la causalidad.

La voluntad de conocimiento en un primer momento de la historia no fue hostil hacia los demás instintos, sino que los instintos sólo eran disciplinados a favor del instinto mismo, de la voluntad de

19 F. Nietzsche, Genealogía de la moral, p. 108. 
poder, es decir, se iban refinando a favor de un progreso. Sin embargo, como la voluntad de poder tiene en su naturaleza la autosupresión, terminó estando a favor de los beneficios y el poder que ofrecía la sociedad, reprimiendo de esta manera los demás instintos, con la finalidad de formar una totalidad coherente y poderosa, algo que superara al individuo.

Fue en la antigüedad, y principalmente en Grecia, donde los juicios de valor se regían bajo presupuestos fisiológicos, se juzgaba lo bueno como lo saludable, como lo poderoso, como ejemplo de ello tenemos a los hombres nobles o aristócratas. Lo bueno como estamento social se diluye en un sinónimo por lo anímicamente fuerte, bueno es el hombre que tiene una salud desbordante. El noble, pues, es el que hace la distinción entre lo que es bueno y verdadero, su propia fuerza le proporciona la veracidad y el estatuto para imponerlo justamente, ya que como ser que domina - pero que no castra sus instintos- sabe guiarse instintivamente hacia todo lo que le fortalece.

Conforme el intelecto abarca más campos en la vida humana, los demás instintos quedan relegados, siendo necesario, como toda cosa que se deja de usar, que se les desconozca, y cuando éstos aparecen lo hacen de forma arbitraria, cada uno quiere salir y demostrar su fuerza, existiendo pues una anarquía de los mismos. Esto sucedió en el ocaso de Grecia, según Nietzsche, los instintos habían caído en una anarquía, existía una especie de degeneración, esa Grecia de la Ilíada llegaba a su fin:

El fanatismo con que la reflexión griega entera se lanza a la racionalidad delata una situación apurada: se estaba en peligro, se tenía una sola elección: o bien perecer o bien ser absurdamente racionales. ${ }^{20}$

Sócrates y Platón fueron los signos más relevantes de esa decadencia que comenzaba; para Nietzsche, ellos son los antigriegos. En la época de éstos surge la dialéctica, un arma para el dominio de los instintos, una cura para la autoconservación. Era necesario ser dueño de uno mismo y, para tal fin, se recurrió al exterminio de las pasiones o instintos, aniquilación que nació instintivamente no en los espíritus fuertes, sino en los espíritus más débiles, quienes incapaces de moderar sus apetitos terminaron por exterminarlos.

20 F. Nietzsche, Crepúsculo de los ídolos, p. 42. 
En todas partes los instintos se encontraban en anarquía; en todas partes se estaba a dos pasos del exceso: el monstruo [... ] era el peligro general. Los instintos quieren hacer de tirano; hay que inventar un contratirano que sea más fuerte. ${ }^{21}$

Los instintos se volvieron unos contra otros. La autodominación no se logró por voluntad libre, sino por un impulso reactivo; lo que se quería era sobrevivir. La razón fue la luz que despejó y ahuyentó la oscuridad de los instintos.

El hombre necesita por fuerza ser inteligente, siempre tender hacia la luz, no desviar la mirada hacia lo oscuro, porque toda mirada desviada es un ir hacia abajo en la evolución.

Después de ver el origen del desarrollo del intelecto, y cómo éste consistía en relacionar los instintos entre sí, siempre en una lucha por el dominio, por alcanzar conglomerados de poder, $y$ al tener en cuenta que el concepto de la voluntad de poder lleva consigo la autosupresión, encontramos que el instinto de causalidad o de conocimiento cae en una serie de errores que no nacen por el cauce natural de la voluntad de poder, sino bajo efectos de hombres débiles en los cuales reside la auténtica corrupción de la voluntad. Uno de ellos es el error de la confusión de la causalidad falsa, de acuerdo a la cual se cree que detrás de toda acción hay una voluntad, una conciencia, o un yo como causa. En la confusión se cree que detrás de toda causa ya sea de la naturaleza o del hombre existe una entidad interna que impulsa a actuar.

El origen del problema o de la corrupción en el uso del intelecto reside, pues, en el olvido de esas ficciones, en donde las ficciones como la causalidad y con ello el ordenamiento del mundo, vitales para la superación y supervivencia del hombre, se olvidan y se vuelven realidades.

El hombre débil, el que ha olvidado que su conocimiento es sólo una serie de ficciones para interpretar el mundo y para prevalecer y dominar a éste mismo, es quien ha desviado la capacidad intelectual del hombre, sin embargo, su razón es fisiológica. Puesto que es el débil, el sometido al hombre poderoso, quien sufre por alcanzar un poco de poder, y es este mismo sufrimiento el que hace nacer un descontento por su realidad, originando un mundo de ficción. Su su-

21 Idem. 
frimiento es el motivo para evadir la realidad, o dicho en palabras de Nietzsche:

Sufrir de la realidad significa ser una realidad fracasada[... La preponderancia de los sentimientos de displacer sobre los de placer es la causa de aquella moral y de aquella religión ficticias: tal preponderancia ofrece, sin embargo, la fórmula de la décadence. $^{22}$

Lo débil, lo que no puede por su misma constitución física decir sí a la vida, al poder, a la belleza, a afirmarse a sí mismo, tuvo que convertir sus instintos debilitados en intelecto, en mero genio y, así, el resentimiento a la vida obligó de cierta manera a creerse las ficciones como realidades, más aún, trajo consigo la creación de nuevas ficciones para soportar este mundo. El hombre débil, para prevalecer y lograr el poder, tuvo que decidir entre ser o existir en este mundo, o no ser en este mundo pero sí en otro; prefirió, pues, el ser a cualquier precio pagando la falsificación de este mundo por otro mejor, pero que no tiene existencia en la vida, sino sólo después de ella.

El decadente tuvo por necesidad que transmutar todos los valores, tuvo que negar todos los instintos, tuvo que ponerlos de revés negando su propia constitución, ya que como hombre decadente, o bien no tenía control sobre sus impulsos, o bien era demasiado débil como para encauzar su fuerza y lograr prevalecer su originario instinto de poderío. Así pues, conforme se subyuga y aniquila el impulso instintal, el hombre está cada vez más encaminado a negar este mundo y buscar otro, se sufre en este mundo sólo con la finalidad de alcanzar un mundo mejor. Por ende, la forma de interpretar el mundo cambia ahora todo efecto, ya sea malo o bueno, se interpreta bajo la forma moral o espiritual, es decir, bajo multiplicidad de agentes detrás de las acciones. Ahora el concepto genuino de causa y efecto se convierte en pecado y premio, el mundo es visto bajo un orden moral, naciendo una causalidad antinatural, que si bien carece de impulso vital para la supervivencia y superación del hombre, es a su vez el principio de una serie de cosas irreales e incompatibles con la vida.

La voluntad de conocimiento se ha trasladado a crear un orden moral del mundo, esto quiere decir que existe la voluntad de un Dios

22 F. Nietzsche, El Anticristo (trad. Andrés Sánchez Pascual), 2.e ed., Madrid, Alianza, 1998, p. 45. 
que decide lo que el hombre debe hacer o dejar de hacer, y que determina el valor del hombre o de un pueblo por su obediencia a él. El conocimiento que yace bajo el concepto del orden moral del mundo se limita a sí mismo, puesto que se ha simplificado y disminuido toda una serie de respuestas a la voluntad de Dios.

De la forma como causa y efecto se moralizan en culpa y premio, y de cómo lo espiritual y la voluntad del hombre se exteriorizan creando multiplicidad de agentes en la naturaleza, es como la realidad se da como algo exterior al hombre, puesto que el mundo -supuestamente verdadero- es el mundo interior, el mundo eterno, el "verdadero mundo" que está en el interior, el cual, nunca es tocado por la realidad y es, a su vez, inaprensible.

Bajo el concepto de orden moral, es decir, de atribuir agentes volitivos y espirituales a las acciones, es como el intelecto busca su causa más allá de la realidad, es decir, al creer que el mundo es producto de una voluntad se está destinado a creer en algo mejor y perfecto que el mundo, creando así los conceptos de ser supremo, bien en sí, lo bello en sí, etcétera. Todos ellos, dada su procedencia, no pueden originarse en un ser perecedero sino más bien en un ser eterno y perfecto. A partir de la concepción y del seguimiento que se tiene sobre la inmortalidad, el hombre siempre tendrá en mayor aprecio el otro mundo, y verá de soslayo y con menosprecio el mundo real, perecedero.

Puesto que ahora los conceptos metafísicos como el bien en sí, el ser supremo, lo bello en sí, sólo son alcanzables por la racionalidad, estos conceptos puros $-y$ sin relación alguna con la realidad, con lo ínfimo- (instintos) descansan sobre conceptos dogmáticos que no tienen relación con la vida sino que vuelan sobre ella. Las cosas puras por su misma constitución no pudieron haber salido de este mundo lleno de errores, pasajero, cambiante, sino en lo inmutable, en lo divino. Se olvida la primigenia finalidad de la voluntad de conocimiento, en donde la importancia no reside en el grado de verdad, sino en su condición vital:

Las cosas de valor sumo es preciso que tengan un origen distinto, propio, - ¡no son derivables de este mundo pasajero, seductor, engañador, mezquino, de esta confusión de delirio y deseo! Antes bien, en el seno del ser, en lo no pasajero, en el Dios oculto, en 
la cosa en sí- ¡ahí es donde tiene que estar su fundamento y en ninguna otra parte! ${ }^{23}$

Los juicios de valor sobre la vida no deben descansar sobre conceptos abstractos, puesto que éstos no tienen relación con la realidad, sino más bien, sólo tienen valor como síntomas. ${ }^{24}$ Es decir, los valores que emitimos son sólo el resultado de los distintos síntomas nacientes de una vida sana o decadente, la vida es un síntoma en cada quien y no es posible medirla, puesto que el hombre como un ser dentro del todo no puede salir de él para así promulgar un juicio objetivo. Asimismo encontramos que el ser débil tiene un juicio de la vida a partir de su vida decadente; cada quien juzga la vida según los síntomas que ésta le provoca.

La vida debe regirse por lo que sea más provechoso, así como el pensamiento debe juzgar lo bueno como un sinónimo de lo saludable. El hombre de voluntad de poderío rige su pensamiento por sus instintos, detrás de toda lógica deben prevalecer exigencias físicas o instintales que permitan el mantenimiento de una vida saludable. Sin embargo, sucede lo contrario en el hombre débil, éste, al despreciar sus instintos, al rechazar su estado animal -el más cercano a la naturaleza-, crea un abismo de conocimiento para determinar lo que le es vital y saludable optando por su lado más racional, más abstracto. Cree, de esta manera, que lo inteligible, lo imposible de conocer y alcanzar (dada su pureza y unidad) es por lo que vale esforzarse, dejando de lado la realidad, tomando por realidades las ficciones de que se vale el conocimiento. Cuando, por otro lado, tenemos que lo único realmente presente o existente es el mundo de los afectos y pasiones, es decir el mundo de los instintos, y sólo por una analogía y por relación podemos hablar del mundo material, y por esto mismo al desviar la mirada de este mundo -el único que nos es dado- hacia caminos imaginarios e irreales el hombre deja de interesarse por lo vital.

Podemos decir, hasta este momento, que la raíz del decaimiento del instinto de conocimiento en su forma genuina es la razón pura sin instintos vitales; el instinto de conocimiento guiado por intenciones morales y no por impulsos vitales. A partir de la anarquía de los instintos fue necesario que la razón los doblegara, de ahí la enfermedad del hombre y su vulnerabilidad a caer de nuevo en la anarquía,

23 F. Nietzsche, Genealogía de la moral, p. 23.

24 Cfr. F. Nietzsche, Crepúsculo de los ídolos. 
propensión ante la cual ha debido imponerse mandatos y reglas de obediencia contrarias al ensanchamiento de su constitución vital. Así, el conocimiento, y con ello, la filosofía, no descansan ya bajo impulsos vitales, sino morales. Puesto que los juicios de valor y de verdad no tienen relación con lo que es vital, sino con lo que haga prevalecer el instinto de conocimiento sin relación con los instintos:

Las intenciones morales (o inmorales) han constituido en toda la filosofía el auténtico germen vital del que ha brotado siempre la planta entera. ${ }^{25}$

Desde el momento en que el filósofo empieza a creer en sí mismo, es decir, en bases y aspiraciones morales, empieza también a crear un mundo a su imagen; ejemplo de ello lo tenemos en Platón, quien crea un mundo de ideas, donde se encuentra lo supremo, el bien en sí, simplemente porque su razón guiada por su moral adversaria de los instintos de lo bajo y oscuro en el hombre, crea un mundo que no tiene lugar para la realidad, para los instintos vitales propios de este mundo cambiante e inestable, y donde su razón puede ser refutada.

Para que la filosofía prevaleciera, para que fuera posible la creación de nuevos mundos, fue necesario que el filósofo se disfrazara de ascético, del tipo de hombre contemplativo, como los sacerdotes, magos o adivinos. Necesitaban pensar en ellos mismos, en lo que les fuera más indispensable, es decir una vida sin perturbación, sin deberes:

El ideal ascético de un filósofo es el óptimum de condiciones de la más alta y osada espiritualidad, y en ello afirma su existencia [...] perezca el mundo, hágase la filosofía, hágase el filósofo, hágame yo. ${ }^{26}$

Sin embargo, el hombre, conforme se aleja cada vez de su constitución natural, es decir, de sus instintos, se vuelve un animal divinizado, espiritual; debilita sus demás instintos y llama virtud al éxito de este debilitamiento.

Se desconfía de todos los sentidos e instintos que pretendan remover el poder que predomina - el instinto de conocimiento-, que no es sino una fuerza que intenta negar la fuente de su fuerza, la vida.

25 F. Nietzsche, Más allá del bien y del mal, p. 26.

26 F. Nietzsche, Crepúsculo de los ídolos, p. 140. 
El filósofo asceta, al rechazar y desconfiar de todo lo que se oponga a la contemplación, a la reflexión y aspiración por lo divino - en donde la razón reina, es decir en el mundo de las ideas, de los conceptos, de lo abstracto y divino-, encuentra el error y la maldad en el cuerpo, en la realidad cambiante, en los sentidos, en todo lo que pueda contradecir a la razón, y por último en la negación de sí mismo. Busca el error en donde el instinto de vida coloca la verdad:

Tiene que ser una necesidad de primer rango la que una y otra vez hace crecer y prosperar esta especie hostil a la vida, tiene que ser sin duda, un interés de la vida misma el que tal tipo de contradicción no se extinga. Pues una vida ascética es una autocontradicción: en ella domina un resentimiento sin igual, el resentimiento de un insaciado instinto y voluntad de poder que quisiera enseñorearse, no de algo existente en la vida, sino de la vida misma, de sus más hondas, fuertes, radicales condiciones; en ella se hace un intento de emplear la fuerza para cegar las fuentes de la fuerza. ${ }^{27}$

De esta manera, hemos visto cómo hay una génesis del instinto de conocimiento. En su finalidad originaria tenía como oficio aumentar la condición vital del hombre, eliminar el sentimiento de extrañeza, aprovechar todo lo útil para el fortalecimiento del cuerpo y del espíritu. El crear ficciones como la causalidad no tenía otro fin que encontrar respuestas que sirvieran para conservar la fuerza y ensancharla, al igual que lo que se tenía entendido como verdad, era verdadero si contribuía a enriquecer anímicamente al hombre, entonces la fuerza del conocimiento no residía en su grado de veracidad, sino en la forma en que armonizaba los demás instintos, no mancillándolos sino ordenándolos, puesto que el orden siempre impone y origina el camino para la creación de conglomerados más grandes de poder que sobrepasen al sujeto.

27 Ibidem, p. 152. 


\section{A modo de conclusión, una posible solución al olvido del sentido original de la voluntad de conocimiento}

El instinto de conocimiento como medio para la superación y el acrecentamiento del poder se ha valido de metáforas, de ficciones, tales como el lenguaje; sin embargo, el hombre, al olvidar que el lenguaje es sólo metáfora, ha proporcionado las primeras leyes para construir lo que se llama verdad. El mundo se ha metaforizado, se ha conceptualizado, es decir, creamos los conceptos para después olvidarnos de las singularidades. El hombre, al olvidar que el conocimiento tiene como finalidad y como carácter una condición vital, se engaña a sí mismo presuponiendo que lo que él crea son verdades que manifiestan lo que constituye la realidad; al olvidar que el lenguaje es sólo metáfora y que nunca podrá aprehender la realidad, olvida también su finalidad. Lo que tiene el hombre son meras metáforas de las cosas que en todos los casos no corresponden a su esencia original, así como los conceptos sirven para interpretar la experiencia singular.

Al crear conceptos nos olvidamos de la realidad y de sus singularidades y sólo en virtud del olvido es como tenemos el sentimiento de verdad. El hecho de creer que la verdad es mejor que la apariencia es meramente un prejuicio moral, ya que si se tuviera presente que el conocimiento nada más se sirve de ilusiones y ficciones, muchos problemas habrían desaparecido, como la búsqueda incansable del ser en sí o lo bueno en sí.

El construir metáforas como un supuesto del conocimiento es completamente necesario para desenvolverse en la vida, no se puede prescindir de él; el error consiste en su olvido, puesto que al crear el lenguaje no se busca ni el bien ni la verdad, sino que es un impulso vital de crear ilusiones que ayuden anímicamente al hombre en su superación, y el impulso hacia la verdad, en cambio, sólo se da dentro de un contexto social:

Ese impulso hacia la construcción de metáforas, ese impulso fundamental del hombre del que no se puede prescindir ni un solo instante, pues si así se hiciese se prescindiría del hombre mismo. $^{28}$

28 F. Nietzsche, Sobre verdad y mentira en sentido extramoral, (trad. Luis M. Valdéz y Teresa Orduvia), 4a. ed., España, Tecnos, 1998, p. 34. 
Si lo que se quiere es recobrar la ingenuidad y la finalidad del instinto de conocimiento, según Nietzsche, es necesario recordar que lo que se considera como la verdad, tiene como finalidad un impulso vital, y que su trasfondo es de origen metafórico; es recordar en sí, el origen metafórico del lenguaje, cuando se está más allá del bien y del mal, cuando se está más allá de lo moral en lo extramoral. Es la búsqueda de imparcialidad en el sentido moral, es el buscar nuevas interpretaciones a los hechos del mundo. La finalidad genuina del conocimiento, para Nietzsche, es la búsqueda de posibilidades y no de certezas, es tener en cuenta que lo que se considera como verdadero no son más que ficciones que han ayudado a interpretar el mundo para así crear posibilidades en el camino de la voluntad de poder, ha de lucharse en contra del olvido y de la imposición de verdades inmutables y dogmáticas que no permiten apreciar el mundo según sus distintas manifestaciones. En la búsqueda de nuevas posibilidades, lo extraño no debe ser erradicado, no dar por supuesto que lo malo y bueno se oponen, y esto es para Nietzsche un primer presupuesto para filosofar de otra manera.

Sin embargo, será necesario matizar la manera en que la voluntad de conocimiento ha de ser removida de su sentido original como un necesario, dada la tesis de la voluntad de poder. Siguiendo a Nietzsche, tenemos entonces que la tesis de la voluntad de poder es sólo un elemento hermenéutico utilizado por él para interpretar el mundo de una manera extramoral, es decir, sin intenciones morales, puesto que nos indica que lo que subyace detrás de los organismos -tales como la naturaleza, y con ella el ser humano- es un conglomerado de fuerzas que luchan por sobresalir y encontrar el poderío, es el incremento de poder que a su vez es la autosupresión, puesto que al engendrar debe quedar superado por su obra. La voluntad de poder es egoísmo, pero no de la persona misma sino de la obra que se está engendrando; debe sacrificarse el propio ser en aras de un ser superior que rebase la singularidad.

De esta manera, encontramos que la voluntad de conocimiento tendrá que transgredir su sentido nato, su finalidad originaria deberá dejarse atrás, puesto que tiene como finalidad algo más complejo, más ordenado.

No obstante, hay que tener en cuenta que tanto en el hombre como en el mundo no existe una finalidad, somos seres arrojados a este mundo sin ninguna intención, por ello mismo no existe una cau- 
salidad moral, es decir, no existe culpa que haya que asignar a algún ser o al ser humano, sino que el transcurso de la vida debe tomarse como algo que es inconsciente, es decir inocente; si se tiene presente esto último, nos dice Nietzsche, se habrá alcanzado la inocencia del devenir. Y es bajo el supuesto del devenir que la voluntad de conocimiento tuvo como necesario adquirir un nuevo sentido, puesto que si quisiéramos cambiar en lo que se ha convertido tendríamos que cambiar el transcurso de la historia del hombre y del mundo y, se podría decir, del hombre como lo conocemos, ya que si se quiere cambiar sería necesario que se cambiara el todo.

En ello radica la voluntad de poder y el carácter trágico del hombre fuerte, en aceptar el devenir, en no querer cambiar nada de la vida aun con sus pormenores o sus sufrimientos, en esto pues, consiste la afirmación máxima de la vida, es decir, en tener el pensamiento del eterno retorno de lo mismo, y en la remisión de este pensamiento a la aceptación de la vida tal como es. Es pues, en última instancia, afirmar la vida hasta sus últimas consecuencias, de un modo radical, en oposición a la aspiración del hombre débil, del nihilista, quien desea desaparecer ciertos aspectos no agradables de la vida o en fin en negarla por completo. 